\title{
Fabrication, Characterization and Thermo- physical Property Evaluation of SiC Nanofluids for Heat Transfer Applications
}

\author{
Nader Nikkam ${ }^{1}$, Mohsin Saleemi ${ }^{1}$, Ehsan B. Haghighi ${ }^{2}$, Morteza Ghanbarpour ${ }^{2}$, Rahmatollah \\ Khodabandeh $^{2}$, Mamoun Muhammed ${ }^{1}$, Björn Palm² ${ }^{2}$ Muhammet S. Toprak ${ }^{1, *}$
}

Received 05 December 2013; accepted 26 January 2014; published online 20 March 2014)

\begin{abstract}
Nanofluids (NFs) are nanotechnology-based colloidal suspensions fabricated by suspending nanoparticles (NPs) in a base liquid. These fluids have shown potential to improve the heat transfer properties of conventional heat transfer fluids. In this study we report in detail on fabrication, characterization and thermo-physical property evaluation of SiC NFs, prepared using SiC NPs with different crystal structures, for heat transfer applications. For this purpose, a series of SiC NFs containing SiC NPs with different crystal structure $(\alpha-\mathrm{SiC}$ and $\beta$-SiC) were fabricated in a water $(\mathrm{W}) /$ ethylene glycol (EG) mixture $(50 / 50$ wt\% ratio). Physicochemical properties of NPs/NFs were characterized by using various techniques, such as powder X-ray diffraction (XRD), scanning electron microscopy (SEM), transmission electron microscopy (TEM), Fouriertransform infrared spectroscopy (FTIR), dynamic light scattering (DLS) and Zeta potential analysis. Thermo-physical properties including thermal conductivity (TC) and viscosity for NFs containing SiC particles ( $\alpha$ - and $\beta$ - phase) weremeasured. The results show among all suspensions NFs fabricated with $\alpha$-SiC particles have more favorable thermo-physical properties compared to the NFs fabricated with $\beta$-SiC.The observed difference is attributed to combination of several factors, including crystal structure ( $\beta$ - vs. $\alpha$-), sample purity, and residual chemicals exhibited on SiCNFs. A TC enhancement of $\sim 20 \%$ while $14 \%$ increased viscosity were obtained for NFs containing $9 \mathrm{wt} \%$ of particular type of $\alpha$-SiC NPs indicating promising capability of this kind of NFs for further heat transfer characteristics investigation.
\end{abstract}

Keywords: SiC nanoparticles; Nanofluids; Thermal conductivity; Viscosity; Thermo-physical property

Citation: Nader Nikkam, Mohsin Saleemi, Ehsan B. Haghighi, Morteza Ghanbarpour, Rahmatollah Khodabandeh, Mamoun Muhammed, Björn Palm and Muhammet S. Toprak, "Fabrication, Characterization and Thermo-physical Property Evaluation of SiCNanofluids for Heat Transfer Applications", Nano-Micro Lett. 6(2), 178-189 (2014). http://dx.doi.org/10.5101/nml.v6i2.p178-189

\section{Introduction}

Heat transfer fluids are involved in many industrial processes to remove excess heat. Conventional heat transfer fluids such as water (W), ethylene glycol (EG) and their mixture (W/EG) have shown poor thermal conductivity (TC) characteristics. On the other hand, developing effective cooling methods for high-tech ap- plications such as transportation, microelectronics, cutting fluid, energy supply, manufacturing and biomedical applications have been prioritized to accelerate further development of these kinds of technologies [1-6]. Hence, conventional working fluids for cooling are being replaced with newer fluids with enhanced TC than the pure and conventional liquids. Pioneer investigations of Choi [7], Lee and Choi [8] and Masuda et al. [9]

\footnotetext{
${ }^{1}$ Department of Materials and Nano Physics, KTH Royal Institute of Technology, SE-16440 Kista-Stockholm, Sweden

${ }^{2}$ Department of Energy Technology, KTH Royal Institute of Technology, SE-10044 Stockholm, Sweden

*Corresponding author. E-mail: toprak@kth.se
} 
reported that the effective TC of suspensions containing suspended nanoparticles (NPs) can be higher than those of normally used industrial heat transfer liquids. Such kind of new fluids, called as nanofluids (NFs), is a new class of dispersions containing nano-sized solid particles (NPs) dispersed in conventional heat transfer fluids as base liquid [7]; and are considered to be new enhanced heat transfer fluids, since they might offer appealing possibilities due to their improved heat transfer performance [10-14]. Consequently, there is a demand for effective and novel heat transfer fluids to solve these challenges. During last decade, there has been a rapid development in NFs preparation methods. There are two major techniques, which are usually utilized for making NFs: one-step method and two-step method. In the one-step method $[10,15]$, NPs are directly prepared in the base liquid, thus forming the NFs in a combined process. Usually, physical vapor deposition (PVD) technique [10], solution chemical method [15] or microwave-assisted route [16] is used for one-step preparation of NFs. There are some advantages in this preparation method, including minimum agglomeration and better stability. In the two-step fabrication method [17-18], NPs are first synthesized/acquired, followed by dispersing them into the base liquid (such as $\mathrm{W}$ or mixture of $\mathrm{W}$ and $\mathrm{EG}$ ) by techniques including high shear [19-20] and ultrasound [21]. Currently, availability of NPs from commercial sources and different suppliers has attractedresearchers to this method, since they can have several choices for a certain nanoparticle, which allow effective and comparative research.

To date, several kinds of solid particles/NPs and base liquids have been utilized in order to fabricate NFs for efficient heat transfer applications: NPs of metals such as $\mathrm{Ag}$ [22], $\mathrm{Cu}$ [23] and $\mathrm{Au}$ [24], oxides such as $\mathrm{Fe}_{3} \mathrm{O}_{4}$, mesoporous $\mathrm{SiO}_{2}, \mathrm{CuO}$ and $\mathrm{Al}_{2} \mathrm{O}_{3}$ [25-28] and carbon based materials such as CNTs [29] are some examples in this regard. Among various materials used for preparing NFs, $\mathrm{SiC}$ is one of the promising materials to fabricate efficient NFs for cooling applications. It has one

Table 1 Summary of available literature on thermo-physical properties of SiC NFs

\begin{tabular}{|c|c|c|c|c|c|c|c|c|}
\hline Material & $\begin{array}{c}\text { Base } \\
\text { Liquid }\end{array}$ & $\begin{array}{c}\text { NP Loading } \\
(\text { wt } \%)\end{array}$ & $\mathrm{pH}$ & Size (nm) & $\mathrm{T}\left({ }^{\circ} \mathrm{C}\right)$ & $\begin{array}{c}\% \mathrm{TC} \\
\text { Enhancement }\end{array}$ & $\begin{array}{l}\% \text { Increase } \\
\text { in Viscosity }\end{array}$ & Ref. \\
\hline \multirow{4}{*}{$\alpha-\mathrm{SiC}$} & \multirow{4}{*}{ W/EG } & \multirow{4}{*}{13} & \multirow{4}{*}{9.4} & $16^{\star}$ & \multirow{4}{*}{22.5} & 1.5 & 52 & \multirow{4}{*}[35]{} \\
\hline & & & & $29^{\star}$ & & 15 & 35 & \\
\hline & & & & $66^{\star}$ & & 15.5 & 22 & \\
\hline & & & & $90^{\star}$ & & 17 & 17 & \\
\hline \multirow{4}{*}{$\alpha-\mathrm{SiC}$} & \multirow{4}{*}{ Water } & \multirow{4}{*}{13} & \multirow{4}{*}{9.4} & $16^{\star}$ & & 7 & 60 & \multirow{4}{*}[34]{} \\
\hline & & & & $29^{\star}$ & 225 & 9.7 & 38 & \\
\hline & & & & $66^{\star}$ & 22.5 & 11.7 & 18 & \\
\hline & & & & $90^{\star}$ & & 12.5 & 17.5 & \\
\hline \multirow{3}{*}{$\mathrm{SiC}$} & \multirow{3}{*}{ Water } & 3 & \multirow{3}{*}{11} & & 22.5 & 3.7 & 102 & \multirow{3}{*}[32]{} \\
\hline & & 6.3 & & & 22.5 & 4.2 & - & \\
\hline & & 9.5 & & & 22.5 & 7.2 & - & \\
\hline \multirow{4}{*}{$\alpha-\mathrm{SiC}$} & & 24 & \multirow{4}{*}{$9-10$} & \multirow{4}{*}{$170 *$} & & 28 & \multirow{4}{*}{$\begin{array}{c}260 \\
38 \\
185\end{array}$} & \multirow{4}{*}{ [33] } \\
\hline & & 3 & & & 70 & 4 & & \\
\hline & & 6 & & & 22.5 & 9 & & \\
\hline & & 12 & & & & 22 & & \\
\hline \multirow{4}{*}{$\alpha-\mathrm{SiC}$} & \multirow{4}{*}{ Water } & \multirow{4}{*}{13.2} & \multirow{4}{*}{10} & $26^{\star}$ & & & \multirow{4}{*}{ Not Reported } & \multirow{4}{*}[31]{} \\
\hline & & & & (spherical) & 4 & 9 & & \\
\hline & & & & $600^{\star}$ & 4 & 16 & & \\
\hline & & & & (Cylinder) & & & & \\
\hline \multirow{4}{*}{$\alpha-\mathrm{SiC}$} & \multirow{4}{*}{ EG } & \multirow{4}{*}{13.2} & \multirow{4}{*}{-} & $26^{\star}$ & & & \multirow{4}{*}{ Not Reported } & \multirow{4}{*}[31]{} \\
\hline & & & & (spherical) & 4 & 10 & & \\
\hline & & & & $600^{\star}$ & 4 & 16 & & \\
\hline & & & & (Cylinder) & & & & \\
\hline
\end{tabular}

*Data obtained by DLS Measurements

${ }^{\star}$ Data estimated from BET measurements 
of the highest TC values (360-490 W/m.K; depending on crystal structure of $\mathrm{SiC}$ ) [30] and is commercially available. Table 1 shows the summary of the literatureson $\mathrm{SiC}$ NFs for heat transfer applications. For the first time, Xie et al. [31] investigated TC of SiC NFs at $4^{\circ} \mathrm{C}$ and reported some TC enhancement methods, yet they did not report on the viscosity of NFs. Won Lee et al. [32] developed water based NFs with $\beta$-SiC NPs and investigated TC and viscosity of suspensions at 9.5 wt\% particle loading. Singh et al. [33] worked on water based commercial suspension containing $\alpha$-SiC NPs and reported about TC and mechanical effects of $\mathrm{SiC}$ NPs in water media. Timofeeva et al. [34] studied the effect of different particle size and interface on thermophysical properties and heat transfer characteristics of water based NFs with $\alpha$-SiC NPs. In another study, Timofeeva et al. [35] reported on a series of NFs with $\alpha$-SiC NPs indifferent base liquids (water and W/EG mixture) and NPs sizes. They have investigated the effect of temperature and base liquid on the heat transfer characteristics of water and W/EG based $\alpha$-SiC NFs.

Although few studies have been performed on the use of $\mathrm{SiC} \mathrm{NF}$ for heat transfer applications, there is no comparative study onthe effect of $\mathrm{SiC}$ crystal structure on the thermo-physical properties of NFs containing $\alpha-\mathrm{SiC}$ and $\beta$-SiC NPs. Therefore, the objective of this work is to fabricate $\mathrm{SiC}$ NFs with different SiCcrystalline phases in order to investigate comparatively physicochemical and thermo-physical properties including TC, and viscosity of SiC NFs in W/EG as the base liquid.

\section{Experimental}

\section{Materials and methods}

Silicon Carbide $(\mathrm{SiC})$ particles with different crystal structures of alpha type $(\alpha-\mathrm{SiC})$ and beta type $(\beta-$
$\mathrm{SiC})$ were purchased from various suppliers/institutes including Superior Graphite (USA), PlasmaChem GmbH (Germany) and ENEA (Italy). Ethylene glycol (EG) and sodium hydroxide $(\mathrm{NaOH})$ were acquired from Sigma Aldrich and Merck KGaA (Germany). All the reagents were used as received without further purification. The materials are abbreviated for ease as shown/listed in Table 2.

\section{Fabrication of $\alpha-\mathrm{SiC}$ NF and $\beta-\mathrm{SiC}$ NF via two- step method}

A series of NFs were fabricated by dispersing a known weight of $\alpha$-SiC and $\beta$-SiC NPs in W/EG (50:50) base liquid, via two-step method. The suspension was sonicated for $15 \mathrm{~min}$ and the $\mathrm{pH}$ value was adjusted to $\sim 9.5$ using $\mathrm{NaOH}$ in order to obtain stable NFs containing $9 \mathrm{wt} \% \alpha$-SiC and $\beta$-SiC NPs. All NFs (Table 3 ) were stable without any visual precipitation within a week. In order to study the real effect of $\alpha$-SiC and $\beta$ $\mathrm{SiC}$ NPs on the thermo-physical properties of NFs, NPs were used as received and the use of surfactant/surface modifiers was avoided. Fabricated NFs were evaluated for TC and viscosity properties. Formulating NFs for obtaining optimum thermo-physical properties such as optimal TC enhancement, minimum impact on viscosity and longer stability is always desired. In this case, several factors such as selection of optimum particle loading play essential role. In this study, the optimum particle loading (9 wt\%) was selected after an extensive test campaign of NFs with various NP concentration, where optimizing basis was maximizing the TC enhancement of NFs with minimal impact of NPs addition on viscosity. Moreover, by doing the literature survey about the relevant research (Table 1) concentration of $9 \mathrm{wt} \%$ was selected in order to achieve NFs with optimal properties. Therefore, all NFs were made with NPs loading of $9 \mathrm{wt} \%$. As Table 1 shows, at higher

Table 2 SiC NPs tested for TC and viscosity

\begin{tabular}{|c|c|c|c|}
\hline Material & Supplier/Institute & NP ID & Surface Area* $\left(\mathrm{m}^{2} / \mathrm{g}\right)$ \\
\hline SiC-Alpha type & Superior Graphite (USA) & $(\alpha 1-\mathrm{SiC})$ & 18 \\
\hline SiC-Alpha type & PlasmaChem GmbH (Germany) & $(\alpha 2-\mathrm{SiC})$ & 18 \\
\hline SiC-Beta type & PlasmaChem GmbH (Germany) & $(\beta 1-\mathrm{SiC})$ & 80 \\
\hline SiC-Beta type & ENEA (Italy) & $(\beta 2-\mathrm{SiC})$ & 90 \\
\hline
\end{tabular}

*Data provided by the supplier.

Table 3 SiC NFs tested for TC and viscosity properties

\begin{tabular}{|c|c|c|c|c|c|}
\hline Sample & NP ID & Crystal Structure & Base Liquid (50:50) by wt $\%$ & NPs loading (wt \%) & $\mathrm{pH}$ \\
\hline$\alpha 1-\mathrm{SiC}$ NF-W/EG & $(\alpha 1-\mathrm{SiC})$ & Hexagonal & $\mathrm{W} / \mathrm{EG}$ & 9 & $\sim 9.5$ \\
\hline$\alpha 2-\mathrm{SiC}$ NF-W/EG & $(\alpha 2-\mathrm{SiC})$ & Hexagonal & W/EG & 9 & $\sim 9.5$ \\
\hline$\beta 1-\mathrm{SiC}$ NF-W/EG & $(\beta 1-\mathrm{SiC})$ & Cubic & W/EG & 9 & $\sim 9.5$ \\
\hline$\beta 2-\mathrm{SiC}$ NF-W/EG & $(\beta 2-\mathrm{SiC})$ & Cubic & $\mathrm{W} / \mathrm{EG}$ & 9 & $\sim 9.5$ \\
\hline
\end{tabular}


concentrations, although NFs with higher TC was achieved, very high viscosity values were observed for NFs, which is unfavorable for their use in practical heat transfer applications.

\section{Characterization techniques}

Microstructure and morphology of $\alpha-\mathrm{SiC}$ and $\beta-\mathrm{SiC}$ particles were evaluated by using scanning electron microscopy (SEM; FEG-HR Zeiss-Ultra 55). Transmission electron microscopy (TEM) analysis of the particles was performed using JEOL 2100 at $200 \mathrm{kV}$ acceleration voltage. Nicolet Avatar IR 360 spectrophotometer, in the range of $500-4000 \mathrm{~cm}^{-1}$ was used for Fourier transform infrared spectroscopy (FTIR) analysis of solid particles and solid/liquid samples. Powder X-ray diffraction (XRD) was performed on a Philips X'pert pro super diffractometer with $\mathrm{Cu} \mathrm{K} \alpha$ source $(\lambda=1.5418 \AA)$. Zeta potential analysis of $\alpha-\mathrm{SiC}$ and $\beta$ $\mathrm{SiC}$ particles was performed for evaluating NFs stability region. Average solvodynamic particle size distribution of $\beta$-SiC particles was evaluated by BeckmannCoulter DelsaNano C system. TC of NFs was measured by using TPS 2500 instrument (HotDisk model 2500), which works based on the Transient Plane Source (TPS) method. The validity of the TPS instrument was checked by comparing with a standard source for thermodynamic properties of water (IAPWS reference) [36]. Compared to the reference the accuracy of measurement for distilled water was within $2 \%$ [36]. Finally, viscosity of NFs was evaluated using a DV-II+ Pro-Brookfield viscometer.

\section{Results and discussion}

\section{XRD analysis}

There are about 250 crystalline forms for Silicon
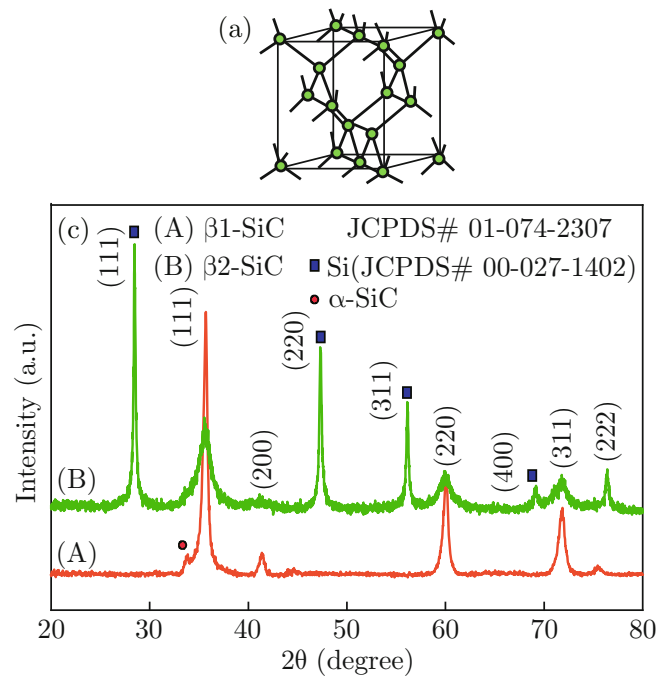

carbide material [37]. Figure 1(a) displays $\beta$-SiC, which is formed at temperatures below $1700^{\circ} \mathrm{C}$, has a cubic crystal structure [38], while as Fig. 1(b) shows the schematics of $\alpha$-SiC, which is formed at temperatures higher than $1700^{\circ} \mathrm{C}$, has a hexagonal crystal structure. In order to identify the crystal structure of SiC NPs, XRD analysis was performed. Figure 1(c) shows the XRD pattern of $\beta 1-\mathrm{SiC}$ and $\beta 2-\mathrm{SiC}$ NPs. The diffraction peaks at $35.8^{\circ}, 41.5^{\circ}, 60.0^{\circ}, 72.0^{\circ}$ and $75.7^{\circ}$ can be indexed as the (111), (200), (220), (311) and (222) reflections of $\beta$-SiC phase, respectively (JCPDS\#01-0742307). The diffraction peak at $34.5^{\circ}$ is attributed to a small amount of $\alpha$-SiC phase. $\beta 2$-SiC sample exhibits excess Si phase and all the extra peaks were indexed with Si reference pattern (JCPDS\#00-027-1402). Figure $1(\mathrm{~d})$ presents the XRD patterns of $\alpha 1-\mathrm{SiC}$ and $\alpha 2$ $\mathrm{SiC}$ particles. Both types of $\alpha-\mathrm{SiC}$ show hexagonal crystal structure and all observed peaks were indexed with the JCPDS \# 01-073-1663 for hexagonal SiC phase.

\section{Morphology analysis}

SEM micrographs of $\alpha-\mathrm{SiC}$ and $\beta$-SiC NPs are presented in Fig. 2(a)-(d). Figure 2(a) and 2(c) represent the spherical morphology of $\beta$-SiCwith estimated primary particle size of $(60 \pm 10) \mathrm{nm}$ and $(30 \pm 10) \mathrm{nm}$ for $\beta 1-\mathrm{SiC}$ and $\beta 2-\mathrm{SiC}$, respectivelywhile Fig. $2(\mathrm{~b})$ and $2(\mathrm{~d})$ present the SEM micrographs of $\alpha 1-\mathrm{SiC}$ and $\alpha 2-\mathrm{SiC}$, respectively. Since there is a very wide size dispersion for both $\alpha 1$ and $\alpha 2$-SiC NPs, it is rather difficult to perform size estimation from the micrographs; however, a rough estimate (by counting $>200$ particles) showed the primary particle size of $(115 \pm 35) \mathrm{nm}$ and $(85 \pm 20)$ $\mathrm{nm}$ for $\alpha 1-\mathrm{SiC}$ and $\alpha 2-\mathrm{SiC}$, respectively. $\mathrm{SiC}$ NPs with $\alpha$-type structure shows larger particle size than $\beta$-type $\mathrm{SiC}$ NPs, which may influence the thermophysical properties of the resultant NFs.

(b)
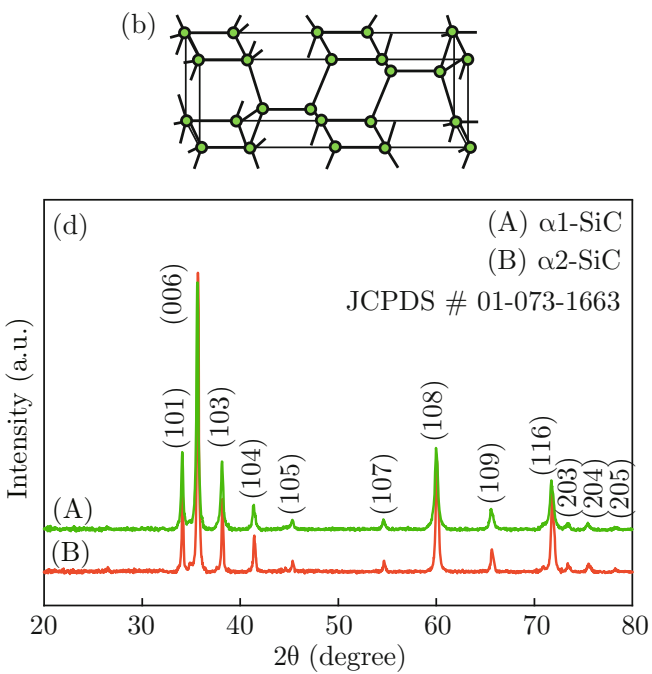

Fig. 1 The unit cell (crystal structure) and XRD pattern of (a, c) $\beta$-SiC and (b, d) $\alpha$-SiC particles, respectively. 

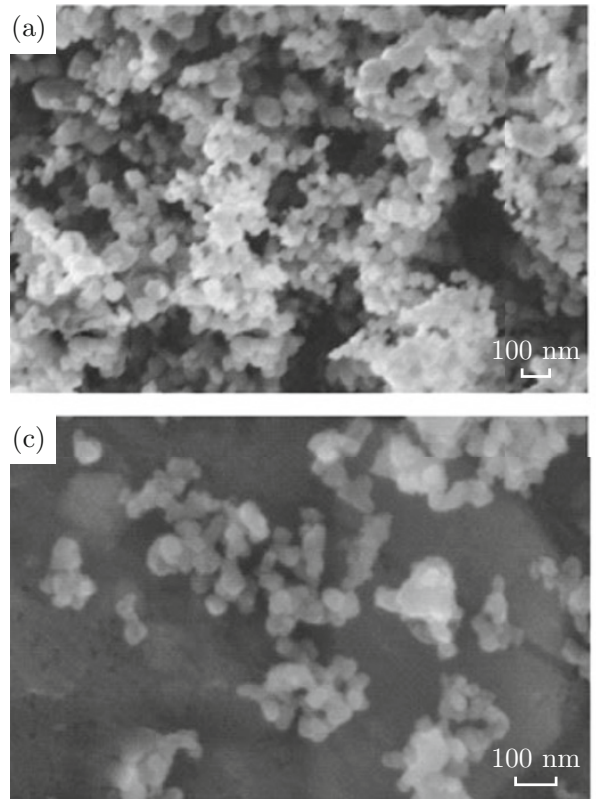
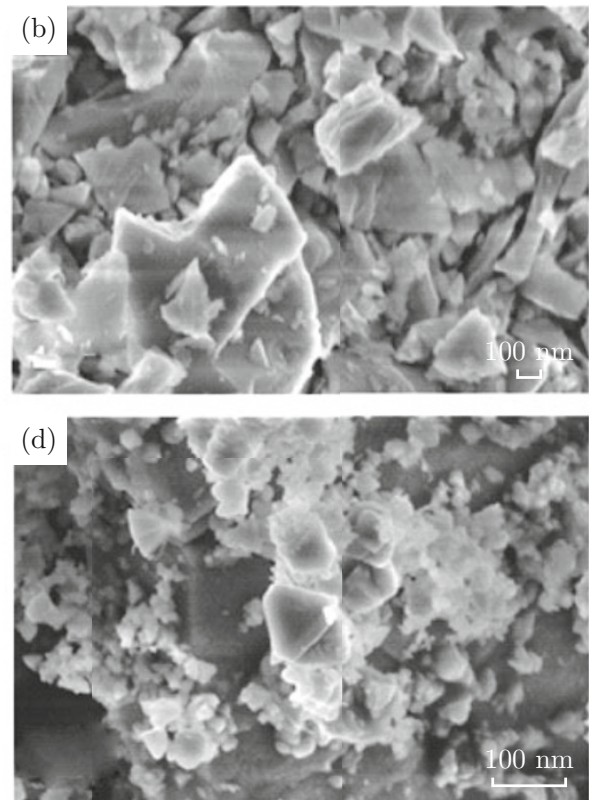

Fig. 2 SEM micrographs of SiC NPs for sample IDs: (a) $\beta 1$; (b) $\alpha 1$; (c) $\beta 2$; (d) $\alpha 2$ (all scale bars are 100 nm.)


Fig. 3 TEM micrograph of SiC particles for samples: (a) $\beta 1$, (b) $\alpha 1$, (c) $\beta 2$ (inset: SAED pattern), (d) $\alpha 2$ (inset: SAED pattern) (all scale bars are $100 \mathrm{~nm}$.).

Figure 3(a)-(d) show the TEM micrographs of $\beta-\mathrm{SiC}$ and $\alpha$-SiC NPs, respectively. Near spherical morphology for $\beta$-SiC NPs was observed (Fig. 3(a) and 3(c)) while hexagonal morphology for $\alpha$-SiC particles were clearly visible (Fig. 3(b) and 3(d)). The morphology of $\alpha$-SiC particles may be dominated by the anisotropic crystal structure, allowing the crystal to grow in certain directions more than the other directions (a.k.a. Crystal habit). Compared to the SEM micrographs presented in Fig. 2(a) and 2(c), $\beta$-SiC NPsin TEM mi- crographs highly agglomerated but much smaller particles were observed. Selected area electron diffraction (SAED) pattern, shown in inset images in Fig. 3(c) and $3(\mathrm{~d})$, were indexed for cubic structure $\beta$-SiC (ICDD No: 01-074-2307) and hexagonal crystal structure $\alpha$ SiC (ICDD No: 01-073-1663), respectively. These electron diffraction results reveal purity and good crystallinity of $\beta$-SiC NPs and $\alpha$-SiC particles. Moreover, there is good match between SAED pattern and XRD analysis. 


\section{Dynamic light scattering (DLS) analysis}

DLS analysis was performed to estimate the dispersed size of SiC NPs in liquid media, in order to understand the influence of effective size of dispersed NPs in the liquid media. DLS analysis results are shown in Fig. 4(a) and 4(b) for both $\alpha$ and $\beta$-SiC in pure water and W/EG media. Figure 4(a) displays DLS results for $\alpha 1-\mathrm{SiC}$ and $\alpha 2-\mathrm{SiC}$ in pure water and W/EG mixture as base liquids. We included pure water in our DLS analysis, since it is also one of the most commonly used base liquids. A wide range of particle size distribution (150$4500 \mathrm{~nm}$ ) with an average peak value of $\sim 1290 \mathrm{~nm}$ was obtained for $\alpha 1-\mathrm{SiC}$ particles in water media. For $\alpha 2$ $\mathrm{SiC}$ in water media, a much wider range of size between $30-10000 \mathrm{~nm}$, with an average peak value of $\sim 1800 \mathrm{~nm}$ has been obtained, indicating strong aggregation of particles in water base liquid. When it comes to W/EG media, both in case of $\alpha 1-$ and $\alpha 2-\mathrm{SiC}$, smaller average sizes with narrower size distribution was observed when compared to the water media, indicating W/EG can affect significantly the dispersion property of $\mathrm{SiC}$ particles. EG may act as dispersant and covalently bond onto the particles surface, which allow stabilization of smaller aggregates/agglomerates as compared to pure water media. In comparison, $\alpha 2$-SiC NPs showed larger dispersed particle size than that of $\alpha 1-\mathrm{SiC}$. The average dispersed size of $\beta$-SiC NPs in both liquids are presented in Fig. 4(b). When $\beta$-SiC NPs were dispersed in pure water it is seen that, the size of $\beta 1-\mathrm{SiC}$ NPs is in the range of $\sim 100-800 \mathrm{~nm}$ with an average diameter of $340 \mathrm{~nm}$ while the size estimation for $\beta 2-\mathrm{SiC}$ in water media showed the range of $130-450 \mathrm{~nm}$ with an average hydrodynamic diameter of $\sim 260 \mathrm{~nm}$. A narrow NPs size distribution with smaller average hydrodynamic size was obtained for $\beta 2-\mathrm{SiC}$ NPs. In W/EG media, the size of $\beta 1-\mathrm{SiC}$ NPs is in the range of $100-450$ $\mathrm{nm}$ with a peak average of $245 \mathrm{~nm}$ while those range and average number are $100-200 \mathrm{~nm}$ and $145 \mathrm{~nm}$ for $\beta 2-\mathrm{SiC}$ NPs. A narrower NPs size distribution with a smaller average dispersed size is estimated for $\beta 2-\mathrm{SiC}$ NPs. In the same way, as observed for $\alpha$-SiC NPs, the presence of EG reduces the aggregate/agglomerate size in the suspensions. Looking at the all results presented in Fig. 4(a) and 4(b), $\beta$-SiC NPs have smaller dispersed size than $\alpha$-SiC NPs, both the NPs exhibit smaller average solvodynamic size in W/EG base liquid compared to the pure water media, indicating a better dispersability in W/EG media. A comparison between SEM, TEM and DLS results for $\beta$-SiC NPs display that for all the $\alpha$ and $\beta$-SiC NPs the primary particle size obtained from SEM and TEM micrographs is less than the predicted sizes from DLS method. This difference may be due to the aggregation/agglomeration of $\alpha$-SiC and $\beta$-SiC NPs in the base liquid media, in addition to the adsorbed liquid layer on particles' surface.
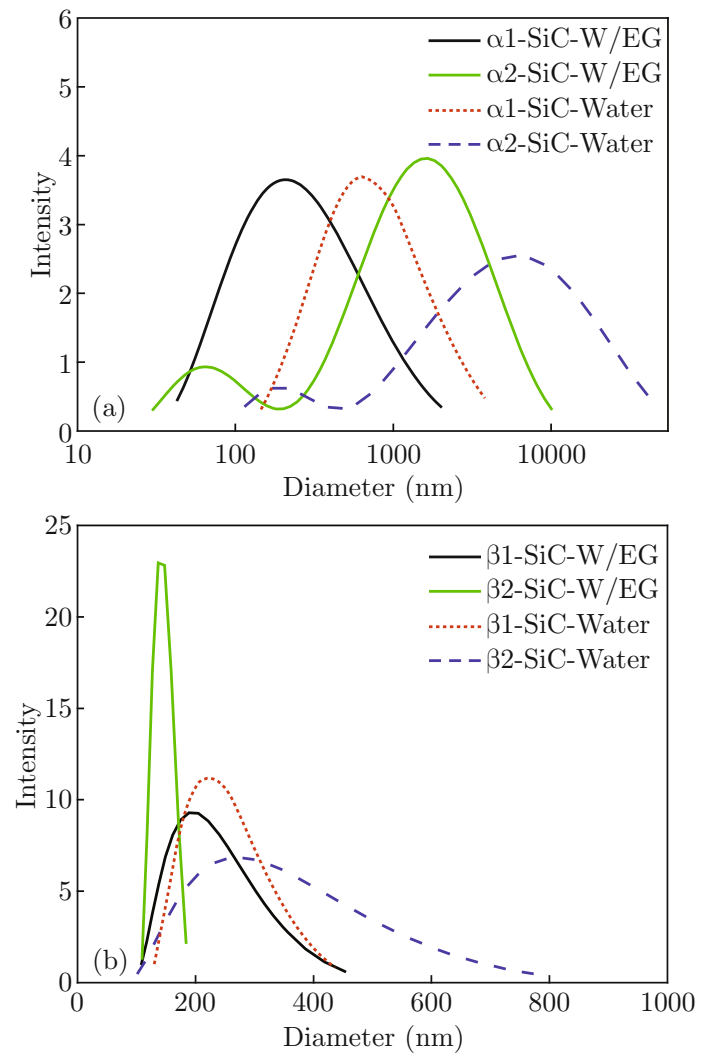

Fig. 4 Particle size distribution of (a) $\alpha-\mathrm{SiC}$ (b) $\beta$-SiC NPs in water and W/EG base liquids measured by DLS.

\section{FTIR analysis}

In order to study the surface characteristics of particles, FTIR analysis was carried out. FTIR spectra for all "as-received" $\mathrm{SiC}$ particles are presented in Fig. 5. The absorption band between $860 \mathrm{~cm}^{-1}$ and $760 \mathrm{~cm}^{-1}$ is attributed to the $\mathrm{Si}-\mathrm{C}$ bond. For all the $\mathrm{SiC}$ particles, the absorption between $1100 \mathrm{~cm}^{-1}$ and $1000 \mathrm{~cm}^{-1}$ are assigned to $\mathrm{Si}-\mathrm{O}-\mathrm{Si}$ or $\mathrm{Si}-\mathrm{O}-\mathrm{C}$ vibrations, respectively. For $\alpha 1-\mathrm{SiC}$ particles theband at $1200 \mathrm{~cm}^{-1}$ is attributed to the $\mathrm{Si}-\mathrm{C}$. $\alpha 2-\mathrm{SiC}$ particles show absorption bands at $1180 \mathrm{~cm}^{-1}$ and $1380 \mathrm{~cm}^{-1}$, which can be attributed to the $\mathrm{Si}-\mathrm{C}$ and amorphous carbon, respectively. Moreover, in both $\alpha 1-\mathrm{SiC}$ and $\alpha 2-\mathrm{SiC}$ particles, there are two bands between 1525 and $1620 \mathrm{~cm}^{-1}$, attributed to the $\mathrm{C}=\mathrm{O}$ groups, which may be due to the un-reacted precursor or residual chemicals due to the method used for their fabrication. By looking at $\beta 1-$ $\mathrm{SiC}$, in addition to $\mathrm{Si}-\mathrm{C}$ bond $\mathrm{Si}-\mathrm{O}-\mathrm{Si}$ at 780 and $1050 \mathrm{~cm}^{-1}$, respectively. There are two more bands at 1200 and $1315 \mathrm{~cm}^{-1}$. The first band is assigned to $\mathrm{Si}-\mathrm{C}$ and the second one to amorphous carbon, respectively. As Fig. 5 shows, compared to other samples, $\beta 1-\mathrm{SiC}$ and $\alpha 2-\mathrm{SiC}$ (both are from the same supplier) present shoulder around $800 \mathrm{~cm}^{-1}$, which may be attributed to the presence of $\mathrm{O}$ at the interface due to the synthesis procedure of high-temperature reduction of $\mathrm{SiO}_{2}$, based on information provided by the supplier 


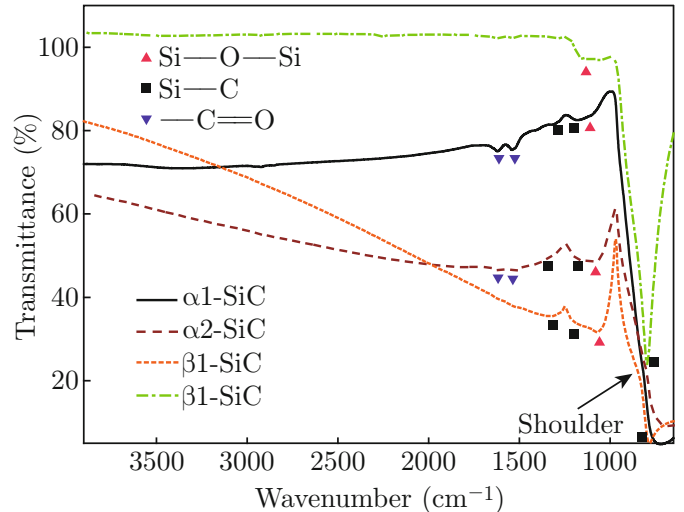

Fig. 5 FTIR spectra of as-received $\beta$ - and $\alpha$-type SiC particles.

[39].

\section{Zeta potential analysis}

Characterizing NPs dispersions and understanding the role of various parameters, which may affect colloidal properties, are important for any NFs. In the literature, very limited investigations can be found on NFs that report on the effect of $\mathrm{pH}$, particle surface chemistry, primary particle size and crystal phase on properties such as Isoelectric Point [40-46]. The $\mathrm{pH}$ of a suspension has important role not only on the rheological property of suspension but also in terms of fabrication of stable suspension, which is related to the electrostatic charge on particles'. It is well known that for fabricating stable NFs, the $\mathrm{pH}$ value of the NF must be far from the Isoelectric Point (IEP), where the overall charge on the particles becomes zero. If the $\mathrm{pH}$ gets close to the IEP the particles tend to agglomerate and finally precipitate, since there are not enough repulsive forces between them. When the $\mathrm{pH}$ is set far from the IEP the absolute electrical charge on particles is increased, which cause repulsive interaction between particles due the collision. In order to identify the optimum $\mathrm{pH}$ values for stable NFs formulation, Zeta potential analyses were performed for both the $\alpha-\mathrm{SiC}$ and $\beta$-SiC particles in the $\mathrm{pH}$ region from 2 to 10 . The results are presented in Fig. 6 where the IEP obtained for the $\alpha-\mathrm{SiC}$ and $\beta$-SiC particles show great variations, one very important common point of exhibiting highly negatively charged particles in the $\mathrm{pH}$ region of $\sim 9.5$ and 10. Therefore, the $\mathrm{pH}$ of NFs was adjusted at 9.5 to obtain stable suspensions. Figure 6 indicates that $\beta$-SiC NPs has higher IEP values compared to the $\alpha$ $\mathrm{SiC}$. The $\alpha 1-\mathrm{SiC}$ and $\alpha 2-\mathrm{SiC}$ particles have very close IEP values in the $\mathrm{pH}$ range of $2-3$, while $\beta$-SiC NPs display similar IEP values in the $\mathrm{pH}$ range of 5-6. The possible reasons for this observation may be due to different synthesis methods of $\mathrm{SiC}$ particles, and impurities present, resulting in different surface chemistry of $\mathrm{SiC}$ particle with $\alpha$ - and $\beta$ - type. As FT-IR analy- sis revealed (Fig. 5), different $\mathrm{SiC}$ NPs exhibited different surface chemistry. By doing a comparison between FT-IR test results and Zeta potential analysis (Fig. 6), one can see that having lower IEP for $\alpha 2-\mathrm{SiC}$ than $\alpha 1$ $\mathrm{SiC}$ may be due to higher silica content (more intensive $\mathrm{Si}-\mathrm{O}-\mathrm{Si}$ bands in FTIR) of $\alpha 2-\mathrm{SiC}$, which shifts the IEP to more acidic pH region (IEP of $\mathrm{SiO}_{2}$ is about 2) [47]. The $\beta 2$-SiC NPs exhibit slightly lower IEP than $\beta 1-\mathrm{SiC}$ NPs. Although $\beta 2-\mathrm{SiC}$ showed higher $\mathrm{Si}-\mathrm{O}-\mathrm{Si}$ bands in FTIR, it exhibited lower IEP due to probably the high content of $\mathrm{Si}$ (assessed from XRD).

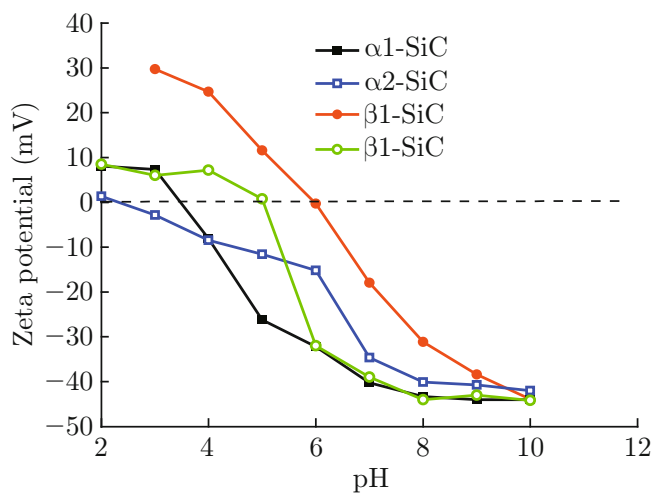

Fig. 6 Zeta potential as a function of $\mathrm{pH}$ for $\beta$ - and $\alpha$ - type $\mathrm{SiC}$ particles.

There are few studies about the NPs' size effect on suspension properties, particularly IEP. The size of particles may not only affect the IEP of the suspension but also the surface reactivity, adsorption affinity and photocatalytic activity of NPs [45-46, 48-49]. As NPs size decreases, the percentage of surface atom/molecule increases extensively. Particle electronic structure, surface defect density and surface sorption sites can be also changed [50-51]. Therefore, both surface reactivity and NPs IEP can become dependent on particle size. There is no report in literature about the impact of $\mathrm{SiC}$ NPs crystal on suspension properties such as IEP. Although there is no systematic study about size effect on $\mathrm{SiC}$ suspension properties yet, there are several reports on $\mathrm{TiO}_{2}$ suspensions and the influence of materials crystal structure on suspension properties $[42,46]$. Kosmulski [42] reported on the effect of crystal phase of $\mathrm{TiO}_{2}$ on IEP and showed that the IEP is rather independent to the crystal structure (rutile vs anatase). The same observation was also repeated by Suttiponparnit et al. [46] when their experimental efforts confirmed that the IEP of $\mathrm{TiO}_{2} \mathrm{NPs}$ was insensitive for the crystal structure of $\mathrm{TiO}_{2}$.

Suttiponparnit et al. [46] studied the role of primary NP size on $\mathrm{TiO}_{2}$ dispersions with different crystal structures (anatase and rutile) and showed that when primary particle size increased, the IEP decreased. In our work, with a focus on size effect on SiC NPs, it can be seen that at the same particle loading of $\mathrm{SiC}$ with 
$\alpha$ type when the primary NP size increased the IEP also increased (primary size has not been calculated for $\alpha$-SiC as the particles are non-spherical, though the magnitude of BET surface area is used for size comparison; large BET surface area revealing smaller primary particles $-\mathrm{c} / \mathrm{o}$ Table 1 ). The same point is valid for $\beta$-SiC, for which an increase of IEP was observed with increasing primary NP size. A two-three orders of magnitude difference between the IEP values of $\alpha-\mathrm{SiC}$ and $\beta$-SiC NPs may also be attributed to be sensitive to the $\mathrm{SiC}$ NPs crystal structure/phase. Our results on IEP of SiC NFs showed that IEP may be affected by the primary size of dispersed particles, impurities involved, and different surface chemistry (due to the fabrication method of particles) of NPs.

\section{TC and viscosity measurements of NFs}

Thermo-physical properties of NFs including TC and viscosity were performed for the all fabricated NFs at $20^{\circ} \mathrm{C}$. In order to evaluate the TC of NFs, $9 \mathrm{wt} \% \mathrm{NFs}$ with $\alpha$-SiC and $\beta$-SiC and W/EG as base liquid were prepared and TPS method was used to test the TC of NFs. The TC evaluation results, measured at $20^{\circ} \mathrm{C}$, are listed in Table 4 , showing higher TC values $\left(K_{n f}\right)$ of all $\mathrm{SiC}$ NFs than the base liquid W/EG. Moreover, Table 4 shows that $\mathrm{TC}$ of $\mathrm{NF}$ with $\alpha$ type $\mathrm{SiC}$ are higher than that of $\beta$ types. The reason is not clear, however, several factors may play the role for facing this difference. It may be due to the dissimilarcrystal structureof $\mathrm{SiC}$ NPs which also have different magnitude of TC (360 $\mathrm{W} / \mathrm{m} \cdot \mathrm{K}$ for $\beta$-and $490 \mathrm{~W} / \mathrm{m} \cdot \mathrm{K}$ for $\alpha$ - type) [30]. This point indicates the possibility of influence of $\mathrm{SiC}$ NPs crystal phase on TC of NFs. The size of NPs may also have a role. The TC results clearly displayed that for all type of $\mathrm{SiC}$ NPs the TC values increase with increasing NP size, which is compatible with the literature [52].

Even sample impurityand different surface chemistry of SiC NPs, as observed from XRD and FTIR analysis,may also result in different TC for NFs. Table 4 also shows that the $\alpha 1-\mathrm{SiC} \mathrm{NF}$ exhibited higher TC values than $\alpha 2-\mathrm{SiC} \mathrm{NF}$. As a result, NF with $\alpha 1-\mathrm{SiC}$ showed the highest TC values, while NF containing $\beta 2-\mathrm{SiC}$ revealed the minimum $\mathrm{TC}$ value which may be due to the all above mentioned reasons such as having largest and smallest particle size for $\alpha 1-\mathrm{SiC}$ NPs and $\beta 2-\mathrm{SiC}$ NPs, respectively. Table 4 lists the relative TC, defined as the ratio of $\mathrm{TC}$ of $\mathrm{SiC}$ NFs $\left(K_{n f}\right)$ over the TC of base liquid $\left(K_{b l}\right)$. The maximum TC enhancement of $20 \%$ was obtained for $\alpha 1-\mathrm{SiC} \mathrm{NF}$ at $20^{\circ} \mathrm{C}$. Timofeeva et al. [35] presented several results for $\alpha$-SiC NFs with W/EG base liquids (Table 1). In the best case they reported $17 \%$ TC enhancement for the particles with average size of $90 \mathrm{~nm}$. A comparison between the TC enhancements of $\alpha 1$ - SiC NF- W/EG (present study) at $20^{\circ} \mathrm{C}$ and that reported by Timofeeva et al. [35], where they used commercial NFs, shows that NFs for the present work has higher TC even at $\sim 4 \mathrm{wt} \%$ lower particle loading, indicating higher effective thermal performance of NF presented in this work.

It is important to clarify that having greater relative $\mathrm{TC}$ value only is not enough for utilizing a NF as effective coolant. In order to choose the efficient NF with optimum characteristics for heat transfer applications, not only TC but also viscosity must be evaluated. The internal resistance of a fluid to flow is described by viscosity [53], which plays an important role in all thermal applications involving flowing fluids [54]. This property is expected to be higher when compared to their base liquids, but this increase makes a negative impact on the pumping power and heat transfer coefficient. These parameters are very essential in practical heat transfer applications. For instance, in laminar flow, the pressure drop is directly proportional to the viscosity. Moreover, Prandtl and Reynolds numbers are influenced by viscosity of fluids and heat transfer coefficient is a function of these numbers. Therefore, viscosity is as important as TC in engineering systems involving fluid flow [55]. This is an important criterion for the use of this type of NFs in convective heat transfer applications. The viscosity tests were carried out at $20^{\circ} \mathrm{C}$ for all NFs with $\mathrm{W} / \mathrm{EG}$ as the base liquid, where all the samples exhibited Newtonian behavior. The results are listed in Table 4 , which show that all NF with $\alpha$ - type SiCparticles have lower viscosity values than NF containing $\beta$ - type SiCparticles. Three possible reasons can be enlisted for the observed difference as the effect of the crystal structure or difference in primary particle size(BET surface area) for $\alpha-\mathrm{SiC} \mathrm{NF}$ and $\beta$-SiC NPs and even to the level of impurities as observed from XRD and FTIR analysis. The smaller surface area of $\alpha$-SiC particles (Table 2) results in a smaller contact (solid-liquid interface) area between $\alpha-\mathrm{SiC}$ particles and $\mathrm{W} / \mathrm{EG}$ base liquid and therefore exhibit smaller viscosity value than

Table 4 TC and viscosity evaluation results of $\mathrm{SiC}$ NFs tested at $20^{\circ} \mathrm{C}$

\begin{tabular}{|c|c|c|c|c|c|}
\hline Sample & NPs loading (wt\%) & $\mathrm{TC}(\mathrm{W} / \mathrm{mk})$ & $K_{n f} / K_{b l}$ & Viscosity $(\mathrm{cP})$ & $\mu_{n f} / \mu_{b l}$ \\
\hline Base Liquid (W/EG) & - & 0.392 & - & 3.897 & - \\
\hline$\alpha 1-\mathrm{SiC}$ NF W/EG & 9 & 0.4704 & 1.20 & 4.4425 & 1.14 \\
\hline$\alpha 2-\mathrm{SiC}$ NF W/EG & 9 & 0.4626 & 1.18 & 4.3646 & 1.12 \\
\hline$\beta 1-\mathrm{SiC} N F \mathrm{~W} / \mathrm{EG}$ & 9 & 0.4469 & 1.14 & 5.299 & 1.36 \\
\hline$\beta 2-\mathrm{SiC} N F \mathrm{~W} / \mathrm{EG}$ & 9 & 0.4195 & 1.07 & 6.2352 & 1.60 \\
\hline
\end{tabular}


$\beta$-SiC at the same particle loading. The increased viscosity values for $\alpha 1-\mathrm{SiC}$ and $\alpha 2-\mathrm{SiC}$ particles are very close as the surface area for both particles are almost the same. Secondly, for the same reason $\alpha 2-\mathrm{SiC} \mathrm{NF}$ exhibited the lowest and $\beta 2$-SiC NFs the highest viscosity values at $20^{\circ} \mathrm{C}$. The relative viscosity, which is defined viscosity of $\mathrm{NF}\left(\mu_{n f}\right)$ to the viscosity of base liquid $\left(\mu_{b l}\right)$, are listed in Table 4 . The minimum increase of $\sim 12 \%$ in viscosity was achieved for $\mathrm{SiC} \mathrm{NF}$ with 9 wt\% $\alpha 2$-SiC particle loading, which has small surface area (larger average particle size), while the maximum increase of $\sim 60 \%$ in viscosity was obtained for $\mathrm{SiC} \mathrm{NF}$ with $\beta 2$-SiC at the same particle loading. NFs containing $\beta 2-\mathrm{SiC}$ exhibit higher increase in viscosity compared to the $\beta 1-\mathrm{SiC} \mathrm{NF}$ at the same NPs loading may be due to its smaller size, and impurity content, which provides a larger surface area per unit volume. A direct comparison between increase of viscosity in this work and the reported values in the literature (Table 1) is not possible because of having different factors such as particle loadings, particle size and dissimilar temperature. Selecting NFs with similar particle loadings, Won Lee et al. [32] reported $7.2 \%$ TC enhancement while increase in viscosity was $102 \%$ for a water based $\beta$-SiC NF with $\sim 9.5 \mathrm{wt} \%$ particle loading indicating that although it exhibit nearly the same relative TC compared to the worst case in this study ( $\beta 2-\mathrm{SiC} \mathrm{NF}$ with $9 \mathrm{wt} \%$ NPs loading), shows $42 \%$ more increase in viscosity. Our findings show favorable thermo-physical properties (higher TC enhancement with lower increase in viscosity) compared to all series of water based $\alpha$-SiC NFs reported by Timofeeva et al. [34] (Table 3). They have utilized commercial water based NFs, prepared by dispersing $\alpha$-SiC NPs, and reported $7-12.5 \%$ TC enhancement with $17.5-60 \%$ increase in viscosity of the NFs containing $13 \mathrm{wt} \%$ of SiC NPs with different sizes. Timofeeva et al. [35] also reported on $\alpha$-SiC NFs with $\mathrm{W} / \mathrm{EG}$ showing $17 \%$ increase in viscosity at $13 \mathrm{wt} \%$ SiC NPs loading (Table 1). The observed differences between this work and Timofeeva et al [34,35] may be due to the different surface chemistry of $\alpha$-SiC particles $(\mathrm{IEP}=4[34])$, type of the base liquid, or additives, besides different NPs loading. The increased viscosity will result in use of a greater pumping power, which might counterweigh the benefits of higher TC enhancement values. The tradeoff between thermo-physical properties including increases in viscosity values and relative TC is very essential in order to utilize the NFs for heat transfer applications.

Figure 7 summarizes the comparison between TC enhancement and viscosity increase, for all fabricated NFs, where both $\alpha$-SiC NFs show that the TC increase is higher than the viscosity increase at $20^{\circ} \mathrm{C}$, while reverse behavior is observed for $\beta$-SiC NFs. This may imply that $\alpha$-SiC NFs formulations can be proper candidates as efficient NFs for convective heat transfer ap- plications. Moreover, a comparison between $\alpha 1-\mathrm{SiC} \mathrm{NF}$ and $\alpha 2-\mathrm{SiC}$ NF shows that although $\alpha 1-\mathrm{SiC}$ NF has $2 \%$ higher viscosity increase, it exhibits $2 \%$ greater TC enhancement value indicating a promising capability of this NF as efficient coolant in heat transfer applications. Among all the fabricated NFs in this work, NFs fabricated by $\alpha 1-\mathrm{SiC}$ particle is the optimum choice, which is therefore selected for further thermal characteristics investigations, and results are to be reported elsewhere.

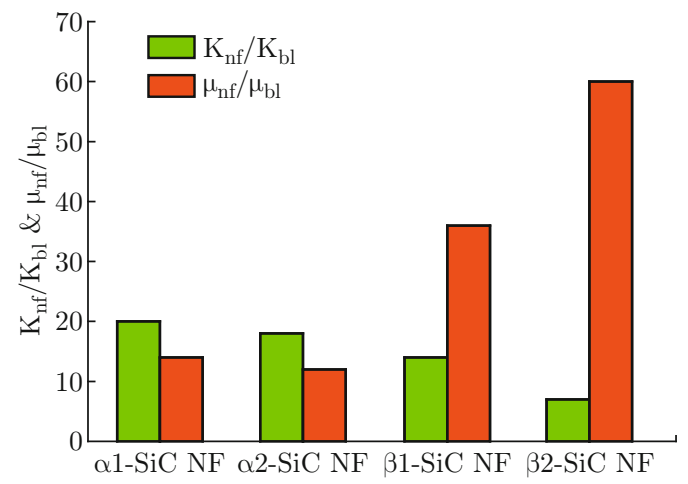

Fig. 7 Comparison of the TC enhancement with increase in viscosity $\left(\right.$ at $20^{\circ} \mathrm{C}$ ) for $\mathrm{NFs}$, with $\mathrm{W} / \mathrm{EG}$ as base liquid, containing 9 wt $\% \alpha$ - and $\beta$ - type $\mathrm{SiC}$ particles.

\section{Conclusions}

We presented on the fabrication and evaluation of highly stable SiCNFs for heat transfer applications. The NFs were prepared by dispersing SiCparticles with different crystal structure in W/EG base liquid, using colloidal stabilization strategies. A detailed physico-chemical evaluation showed different characteristics of $\mathrm{SiC} \mathrm{NPs}$, including crystal structure, primary/dispersed particle size, surface functionality, surface charge, and purity levels of SiCNPs used. Interpretation of the results from different analytical techniques showed that IEP of the SiC NPs, and the viscosity of NFs, may be affected by the primary size, surface chemistry of NPs (due to the different NPs fabrication routes), as they may also be dependent on $\mathrm{SiC}$ crystal structure ( $\alpha$ - vs. $\beta$ - type). Thermo-physical properties, $\mathrm{TC}$ and viscosity, of $\mathrm{SiC}$ NFs were performed at $9 \mathrm{wt} \%$ NPs loading at $20^{\circ} \mathrm{C}$. TC enhancement of the NF, over the base liquid, due to the presence of $\mathrm{SiC}$ particles are observed for NFs containing both $\alpha$ - and $\beta$-type SiCNPs. W/EG based NFs with $\alpha$-SiC exhibited higher $\mathrm{TC}$ than that with $\beta$-SiC, which may be attributed to the effect of the crystal structure (as $\alpha$-type has higher $\mathrm{TC}$ value), or the phase purity of the as-received materials. Among all fabricated W/EG based NFs containing SiCwith different crystal structure ( $\alpha$ - vs. $\beta$ - type), $\alpha 1-\mathrm{SiC}$ NF displayed the highest TC enhancement of $20 \%$, while only $14 \%$ increase in viscosity,revealing its 
promising characteristics for heat transfer applications.

\section{Acknowledgments}

The financial support from the EU (Project Reference: 228882) and Swedish Research Council (VR) for the project NanoHex (Enhanced Nano-fluid Heat Exchange) is highly appreciated.

\section{References}

[1] Q. X. Wang and A. S. Mujumdar, "A Review on nanofluids-Part I: Theoretical and numerical investigations", Braz. J. Chem. Eng. 25(4), 613-630 (2008). http://dx.doi.org/10.1590/ S0104-66322008000400001

[2] S. Senthilraja, M. Karthikeyan and R. Gangadevi, "Nanofluid applications in future automobiles: Comprehensive review of existing data", Nano-Micro Lett. 2(4), 306-310 (2010). http://dx.doi.org/10.3786/ nml.v2i4.p306-310

[3] K. Y. Leong, R. Saidur, S. N. Kazi and A. H. Mamun, "Performance investigation of an automotive car radiator operated with nanofluid-based coolants (nanofluid as a coolant in a radiator)", Appl. Therm. Eng. 30(1718), 2685-2692 (2010). http://dx.doi.org/10.1016/ j.applthermaleng . 2010.07.019

[4] V. Vasu and K. M. Kumar, "Analysis of nanofluids as cutting fluid in grinding EN-31 steel", Nano-Micro Lett. 3(4), 209-214 (2011). http://dx.doi.org/10. $3786 / \mathrm{nml}$.v3i4.p209-214

[5] C. H. Li and G. P. Peterson, "Experimental investigation of temperature and volume fraction variations on the effective thermal conductivity of nanoparticle suspensions (nanofluids)", J. Appl. Phys. 99(8), 084314-8 (2006). http://dx.doi.org/10.1063/1.2191571

[6] H. Zhu, C. Zhang, S. Liu, Y. Tang and Y. Yin, "Effects of nanoparticles clustering and alignment on thermal conductivities of $\mathrm{Fe}_{3} \mathrm{O}_{4}$ aqueous nanofluids", Appl. Phys. Lett. 89(2), 023123-3 (2006). http://dx.doi. org/+10.1063/1.2221905

[7] S. U. S. Choi, "In development and applications of non-Newtonian flows", edited by D.A. Siginer et al. New York: ASME 99-105 (1995).

[8] S. Lee S and S. U. S. Choi, "Application of metallic nanoparticle suspension in advanced cooling systems". Proceedings of Recent Advances in Solids/Structures, vol. 342/MD-vol. 72, ASME, USA, New York 227-234 (1996).

[9] H. Masuda, A. Ebata, K. Teramae and N. Hishinuma, "Alteration of thermal conductivity and viscosity of liquid by dispersing ultra-fine particles. Dispersion of $\mathrm{Al}_{2} \mathrm{O}_{3}, \mathrm{SiO}_{2}$ and $\mathrm{TiO}_{2}$ ultra-fine particles", Jpn. J. Thermophys. Prop. 7(4), 227-233 (1993). http://dx. doi.org/10.2963/jjtp.7.227

[10] J. Eastman, S. Choi, S. Li, W. Yu and L. Thompson, "Anomalously increased effective thermal conductivities of ethylene glycol-based nanofluids containing cop- per nanoparticles", Appl. Phys. Lett. 78(6), 718-720 (2001). http://dx.doi.org/10.1063/1.1341218

[11] S. U. S. Choi S, Z. G. Zhang and W. Yu, F. E. Lockwood and E. A. Grulke, "Anomalous thermal conductivity enhancement in nanotube suspensions", Appl. Phys. Lett. 79(14), 2252-2254 (2001). http://dx.doi. org/10.1063/1.1408272

[12] H. E. Patel, S. K. Das, T. Sundararajan, A. S. Nair, B. George and T. Pradeep, "Thermal conductivities of naked and monolayer protected metal nanoparticle based nanofluids: Manifestation of anomalous enhancement and chemical effects", Appl. Phys. Lett. 83(14), 2931-2933 (2003). http://dx.doi.org/10. 1063/1. 1602578

[13] P. Vassallo, R. Kumar and S. D‘Amico, "Pool boiling heat transfer experiments in silica-water nano-fluids", Int. J. Heat Mass Trans. 47(2), 407-411 (2004). http://dx.doi.org/10.1016/ S0017-9310(03) 00361-2

[14] P. Keblinski, J. A. Eastman and D. G. Cahill, "Nanofluids for thermal transport", Mater. Today 8(6), 36-44 (2005). http://dx.doi.org/10.1016/ S1369-7021(05) 70936-6

[15] H. T. Zhu, Y. S. Lin and Y. S. Yin, "A novel one-step chemical method for preparation of copper nanofluids", J. Colloid Interface Sci. 277(1), 100-103 (2004). http://dx.doi.org/10.1016/j.jcis.2004.04.026

[16] S. U. Shenoy and A. N. Shetty, "Synthesis of copper nanofluids using ascorbic acid reduction method via one step solution phase approach", J. ASTM Int. 9(5), 1-13 (2012). http://dx.doi.org/10.1520/JAI104416

[17] G. Paul, J. Philip, B. Raj, P. K. Das and I. Manna, "Synthesis characterization and thermal property measurement of nano- $\mathrm{Al}_{95} \mathrm{Zn}_{05}$ dispersed nanofluid prepared by a two-step process", Int. J. Heat Mass Tran. 54(15-16), 3783-3788 (2011). http://dx.doi.org/10. 1016/j.ijheatmasstransfer. 2011.02.044

[18] W. Yu, H. Xie, Y. Li and L. Chen, "Experimental investigation on thermal conductivity and viscosity of aluminum nitride nanofluid", Particuology 9(2), 187191 (2011). http://dx.doi.org/10.1016/j.partic. 2010.05 .014

[19] B. C. Pak and Y. I. Cho, "Hydrodynamic and heat transfer study of dispersed fluids with submicron metallic oxide particles", Exp. Heat Transfer 11(2), 151-170 (1998). http://dx.doi.org/10.1080/ 08916159808946559

[20] D. Wen and Y. Ding, "Formulation of nanofluids for natural convective heat transfer applications", Int. J. Heat Fluid Flow 26(6), 855-864 (2005). http://dx. doi.org/10.1016/j.ijheatfluidflow. 2005.10.005

[21] E. Goharshadi, Y. Ding, M. Jorabchi and P. Nancarrow, "Ultrasound-assisted green synthesis of nanocrystallineZnO in the ionic liquid [hmim] $\left[\mathrm{NTf}_{2}\right]$ ", Ultrason. Sonochem. 16(1), 120-123 (2009). http://dx. doi.org/10.1016/j.ultsonch. 2008.05.017

[22] P. Sharma, I. Baek, T. Cho, S. Park and K. B. Lee, "Enhancement of thermal conductivity of ethylene glycol based silver nanofluids", Powder Technol. 208(1), 
7-19 (2011). http://dx.doi.org/10.1016/j.powtec. 2010.11 .016

[23] J. Garg, B. Poudel, M. Chiesa, J. B. Gordon, J. J. Ma, J. B. Wang, Z. F. Ren, Y. T. Kang, H. Ohtani, J. Nanda, G. H. McKinley and G. Chen, "Enhanced thermal conductivity and viscosity of copper nanoparticles in ethylene glycol nanofluid", J. Appl. Phys. 103(7), 074301-6 (2008). http://dx.doi.org/ 10.1063/1.2902483

[24] H. J. Kim, I. C. Bang and J. Onoe, "Characteristic stability of bare Au-water nanofluids fabricated by pulsed laser ablation in liquids", Opt. Laser Eng. 47(5), 532-538 (2009). http://dx.doi.org/10.1016/ j.optlaseng. 2008.10.011

[25] Y. Tan, Y. Zheng, N. Wang and A. Zhang, "Controlling the properties of solvent-free $\mathrm{Fe}_{3} \mathrm{O}_{4}$ nanofluids by corona structure", Nano-Micro Lett. 4(4), 208214 (2012). http://dx.doi.org/10.3786/nml.v4i4. p208-214

[26] N. Nikkam, M. Saleemi, M. Toprak, S. Li, M. Muahmmed, E. B. Haghighi, R. Khodabandeh, B. Palm, "Novel nanofluids based on mesoporous silica for enhanced heat transfer", J. Nanopart. Res. 13(11), 6201-6206 (2011). http://dx.doi.org/10. 1007/s11051-011-0404-1

[27] S. Lee, S. U. S. Choi, S. Li and J.A. Eastman, "Measuring thermal conductivity of fluids containing oxide nanoparticles", ASME J. Heat Transf. 121(2), 280-289 (1999).

[28] K. V. Wong and T. Kurma, "Transport properties of alumina nanofluids", Nanotechnology 19(34), 345702-8 (2008). http://dx.doi.org/10.1115/1.2825978

[29] A. Amrollahi, A. A. Hamidi and A. M. Rashidi, "The effects of temperature, volume fraction and vibration time on the thermo-physical properties of a carbon nanotube suspension (carbon nanofluid)", Nanotechnology 19(31), 315701-8 (2008). http://dx.doi.org/ 10.1088/0957-4484/19/31/315701

[30] R. A. Andrievski, "Synthesis, structure and properties of nanosized silicon carbide", Rev.Adv.Mater.Sci. 22, 1-20 (2009).

[31] H. Xie, J. Wang, T. Xi and Y. Liu, "Thermal conductivity of suspensions containing nanosizedSiC particles", Int. J. Thermophys. 23(2), 571-580 (2002). http://dx.doi.org/10.1023/A: 1015121805842

[32] S. W. Lee, S. D. Park, S. Kang, I. C. Bang and J. H. Kim, "Investigation of viscosity and thermal conductivity of SiCnanofluids for heat transfer applications", Int. J. Heat Mass. Tran. 54(13), 433-438 (2011). http://dx.doi.org/10.1016/j. ijheatmasstransfer.2010.09.026

[33] D. Singh, E. Timofeeva, W. Yu, J. Routbort, D. France, D. Smith and J. M. Lopez-Cepero, "An investigation of silicon carbide-water nanofluid for heat transfer applications", J. Appl. Phys. 105(6), 064306 - 064306-6 (2009). http://dx.doi.org/10.1063/1. 3082094

[34] E. V. Timofeeva, D. S. Smith, W. Yu, D. M. France, D. Singh, J. L. Routbort, "Particle size and interfa- cial effects on thermo-physical and heat transfer characteristics of water-based $\alpha$-SiCnanofluids", Nanotechnology 21(21), 215703-10 (2010). http://dx.doi.org/ 10.1088/0957-4484/21/21/215703

[35] E. V. Timofeeva, W. Yu, D. M .France, D. Singh and J. L. Routbort, "Base fluid and temperature effects on the heat transfer characteristics of $\mathrm{SiC}$ in ethylene glycol $/ \mathrm{H}_{2} \mathrm{O}$ and $\mathrm{H}_{2} \mathrm{O}$ nanofluids", J. Appl. Phys. 109(1), 014914 (2011). http://dx.doi.org/10.1063/ 1. 3524274

[36] E. B. Haghighi, Z. Anwar, I. Lumbreras, S. A. Mirmohammadi, M. Behi and R. Khodabandeh and B. Palm, "Screening single phase laminar convective heat transfer of nanofluids in a micro-tube", J. Phys. Conf. Ser. 395(1), 012036-11 (2012). http://dx.doi.org/ 10.1088/1742-6596/395/1/012036

[37] R. Cheung, "Silicon carbide microelectromechanical systems for harsh environments", Imperial College, pp3 (2006).

[38] T. Muranaka, Y. Kikuchi, T. Yoshizawa, N. Shirakawa and J. Akimitsu, "Superconductivity in carrierdoped silicon carbide", Sci. Technol. Adv. Mater. 9(4), 044204-8 (2008). http://dx.doi.org/10.1088/ 1468-6996/9/4/044204

[39] Y. P. Guo, J. C. Zheng, A. T. S. Wee, C. H. A. Huan, K. Li, J. S. Pan, Z. C. Feng and S. J. Chua, "Photoluminescence studies of SiCnanocrystals embedded in a $\mathrm{SiO}_{2}$ matrix", Chem. Phys.Lett. 339(5-6), 319-322 (2001). http://dx.doi.org/10. 1016/S0009-2614(01)00308-6

[40] Jingkun Jiang, Günter Oberdörster, Pratim Biswas "Characterization of size, surface charge, and agglomeration state of nanoparticle dispersions for toxicological studies", J. Nanopart. Res. 11(1), 77-89 (2009). http://dx.doi.org/10.1007/ s11051-008-9446-4

[41] M. Kosmulski, "pH-dependent surface charging and points of zero charge. IV. Update and new approach", J.Colloid Interface Sci. 337(2), 439-448 (2009). http://dx.doi.org/10.1016/j.jcis.2009.04.072

[42] M. Kosmulski, "The significance of the difference in the point of zero charge between rutile and anatase", Adv. Colloid Interface Sci. 99(3), 255-264 (2002). http:// $\mathrm{dx}$.doi .org/10.1016/S0001-8686(02)00080-5

[43] J. Jiang, G. Oberdörster, A. Elder, R. Gelein, P. Mercer and P. Biswas, "Does nanoparticle activity depend upon size and crystal phase?", Nanotoxicology 2(1), 33-42 (2008). http://dx.doi.org/10.1080/ 17435390701882478

[44] Y. Gao, R. Wahi, A. T. Kan, J. C. Falkner, V. L. Colvin and A. B. Tomson, "Adsorption of cadmium on anatase nanoparticles effect of crystal size and pH", Langmuir 20(22), 9585-9593 (2004).

[45] D. E. Giammar, C. J. Maus and L. Y. Xie, "Effects of particle size and crystalline phase on lead adsorption to titanium dioxide nanoparticles", Environ. Eng. Sci. 24(1), 85-95 (2007). http://dx. doi .org/10. 1089/ees. 2007.24.85 
[46] K. Suttiponparnit, J. Jiang, M. Sahu, S. Suvachittanont, T. Charinpanitkul and P. Biswas, "Role of surface area, primary particle size, and crystal phase on titanium dioxide nanoparticle dispersion properties", Nanoscale Res. Lett. 6(27), 2-8 (2011). http://dx. doi.org/10.1007/s11671-010-9772-1

[47] K. Kamada, M. Tokutomi, N. Enomoto and H. Junichi, "Incorporation of oxide nanoparticles into barrier-type alumina film via anodic oxidation combined with electrophoretic deposition", J. Mater. Chem. 15, 3388-3394 (2005). http://dx.doi.org/10. 1039/B504364F

[48] A. Sclafani and J. M. Herrmann, "Comparison of the photoelectronic and photocatalytic activities of various anatase and rutile forms of titania in pure liquid organic phases and in aqueous solutions", J. Phys. Chem. 100 (32), 13655-13661 (1996). http://dx.doi. org/10.1021/jp9533584

[49] Oman Zuas, Harry Budiman, "Synthesis of nanostructured copper-doped titania and its properties", NanoMicro Lett. 5 (1), 26-33 (2013). http://dx.doi.org/ 10.3786/nml.v5i1.p26-33

[50] G. A. Waychunas, C. S. Kim and J. F. Banfield, "Nanoparticulate iron oxide minerals in soils and sediments: unique properties and contaminant scavenging mechanisms", J. Nanopart. Res.
7(4-5), 409-433 (2005). http://dx.doi.org/10.1007/ s11051-005-6931-x

[51] B. Gilbert and J. F. Banfield, "Molecular-Scale Processes Involving Nanoparticulate Minerals in Biogeochemical Systems", Rev. Mineral. Geochem. 59, 109155 (2005). http://dx.doi.org/10.2138/rmg. 2005. 59.6

[52] E. V. Timofeeva, W. Yu, D. M. France, D. Singh and J. L. Routbort, "Nanofluids for heat transfer: an engineering approach" Nanoscale Res. Lett. 6(182), 2-7 (2011). http://dx.doi.org/10.1186/ 1556-276X-6-182

[53] C. Nguyen, F. Desgranges, G. Roy, N. Galanis, T. Mare, S. Boucher and H. A. Mintsa, "Temperature and particle-size dependent viscosity data for waterbased nanofluids - hysteresis phenomenon", Int. J. Heat Fluid Flow 28(6), 1492-1506 (2007). http://dx. doi.org/10.1016/j.ijheatfluidflow.2007.02.004

[54] P. K. Namburu, D. P. Kulkarni, A. Dandekar and D. K. Das, "Experimental investigation of viscosity and specific heat of silicon dioxide nanofluids", Micro NanoLett. 2(3), 67-71 (2007). http://dx.doi.org/10. 1049/mnl : 20070037

[55] M. Kole M and T. K. Dey, "Viscosity of alumina nanoparticles dispersed in car engine coolant", Exp. Therm. Fluid Sci. 34(6), 677-683 (2010). http://dx. doi.org/10.1016/j.expthermflusci.2009.12.009 